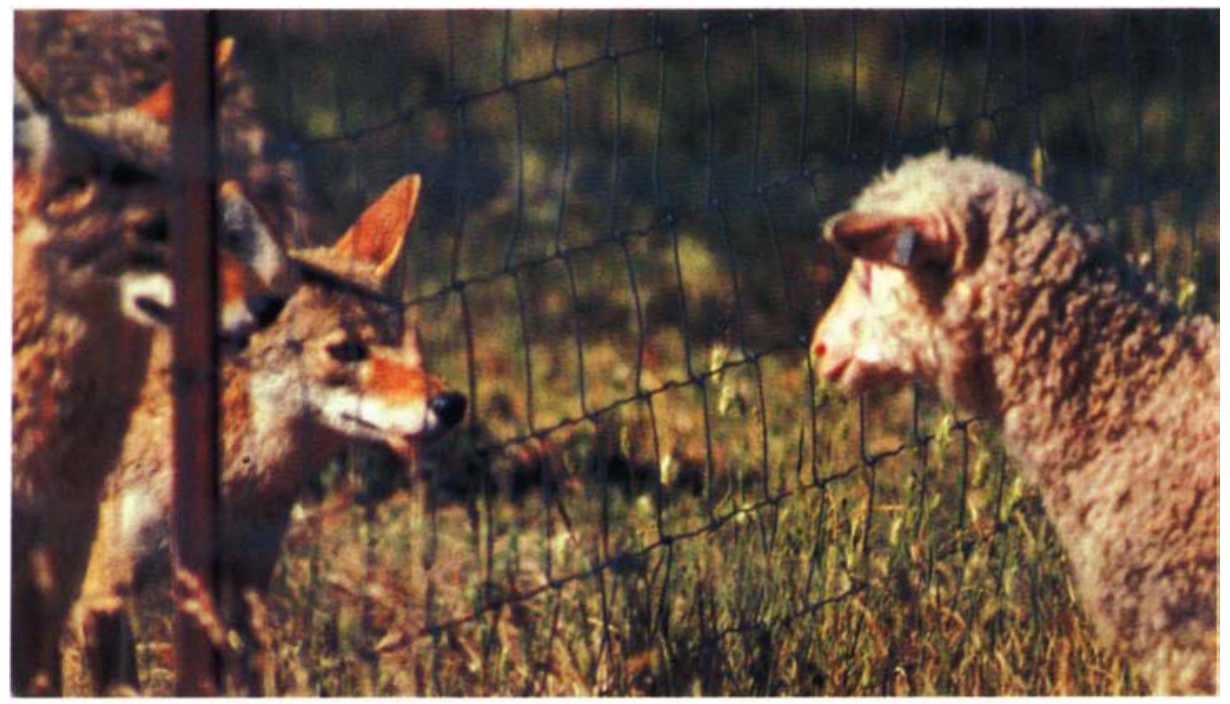

At the UC Hopland Research and Extension Center, sheep are subject to the same management problems typically experienced by sheep producers on California's North Coast, including coyote depredation. In the early 1970s, coyotes were observed in fenced enclosures to better understand their sheep-killing instincts.

\section{Sheep-killing coyotes a continuing dilemma for ranchers}

\author{
Robert M. Timm $\square$ Guy E. Connolly
}

changing economic conditions (such as falling lamb prices and increasing labor costs) and land uses (including rural residential and vineyard development) led to declining sheep numbers. Concurrently, public attitudes toward predator control began to change. New residents typically did not have close ties to the livestock ranching community or to agriculture.

County and federal wildlife specialists responded to ranchers' requests for assistance, typically controlling depredating coyotes by traditional means (Connolly and Longhurst 1975). These included leg-hold traps, poisons, snares and shooting, sometimes with the aid of decoy dogs. All of these methods were used with the goal of keeping the number of predators low to reduce damage to the sheep (Hackett 1990). As losses increased, producers adopted a wider array of nonlethal methods, including traditional and electric fencing, keeping lambs and other vulnerable animals near areas of human activity, lambing in sheds or small, securely fenced lots, and even penning livestock at night.

\section{Unacceptable losses}

Despite such efforts, livestock losses in parts of the North Coast region reached unacceptable levels by the 1970s (Larson and Salmon 1988; Coolahan 1990), a trend that was exacerbated by the 1972 federal ban on using toxicants to control predators. As the sheep industry declined, Mendocino County flocks dropped from 117,900 sheep and lambs in 1962 to a low of 16,000 in 1995 (Agricultural Commissioner 1962, 1995), with a parallel rate of decline noted in Humboldt County (Hackett 1990).

Even with depressed sheep numbers statewide, California producers reported losing to predators 9,350 adult sheep valued at $\$ 794,750$, which was $2.0 \%$ of the state inventory on Jan. 1,1994 , of breeding sheep one year and older (400,000 head) plus replacement lambs (65,000 head). Also lost to predators were 26,575 lambs valued at 
$\$ 1,036,425,6.6 \%$ of the state inventory of market lambs on Jan. 1, 1994. Producers in California reported spending an average of $\$ 3.50$ per breeding head on predator control efforts in 1994 (Simpson 1995; NASS 1999).

At HREC, three-quarters of the livestock losses to predators have been attributed to coyotes. Other predators that have killed sheep or lambs include stray dogs, bears, golden eagles and, since the mid-1980s, mountain lions. We believe that the increased abundance of predators is a main reason why the center's research sheep flock has suffered rising levels of loss during the last three decades. Hopland's sheep and lambs represent a loss that exceeds their commercial value, because they are often used simultaneously in one or more research projects; if they are killed or injured the research is jeopardized.

The pattern of sheep losses experienced at Hopland since 1973 is typical of ranches in the North Coast region. Young lambs are more vulnerable to coyote predation than adult sheep. Increased lamb loss is evident over time, expressed either as total lambs lost or as a percentage of all available lambs (fig. 1). While missing lambs may have died due to causes other than coyote predation, Scrivner et al. (1985) and Taylor et al. (1978) attributed to coyote predation the same percentage of missing lambs as was proven from recovered lamb carcasses. Scrivner et al (1985) calculated that $45 \%$ of missing lambs were lost due to coyotes from 1973 through 1983. This is a reasonable estimate of average loss to coyotes for 1984 through 1999 as well.

From the early 1970s until 1992, HREC practiced traditional coyote control, with a government wildlife damage control specialist working year-round to remove predators from a large district that included the HREC. This strategy changed when the U.S. Department of Agriculture (USDA) and UC Berkeley initiated an intensive coyote behavior study.

From March 1993 through Sep-

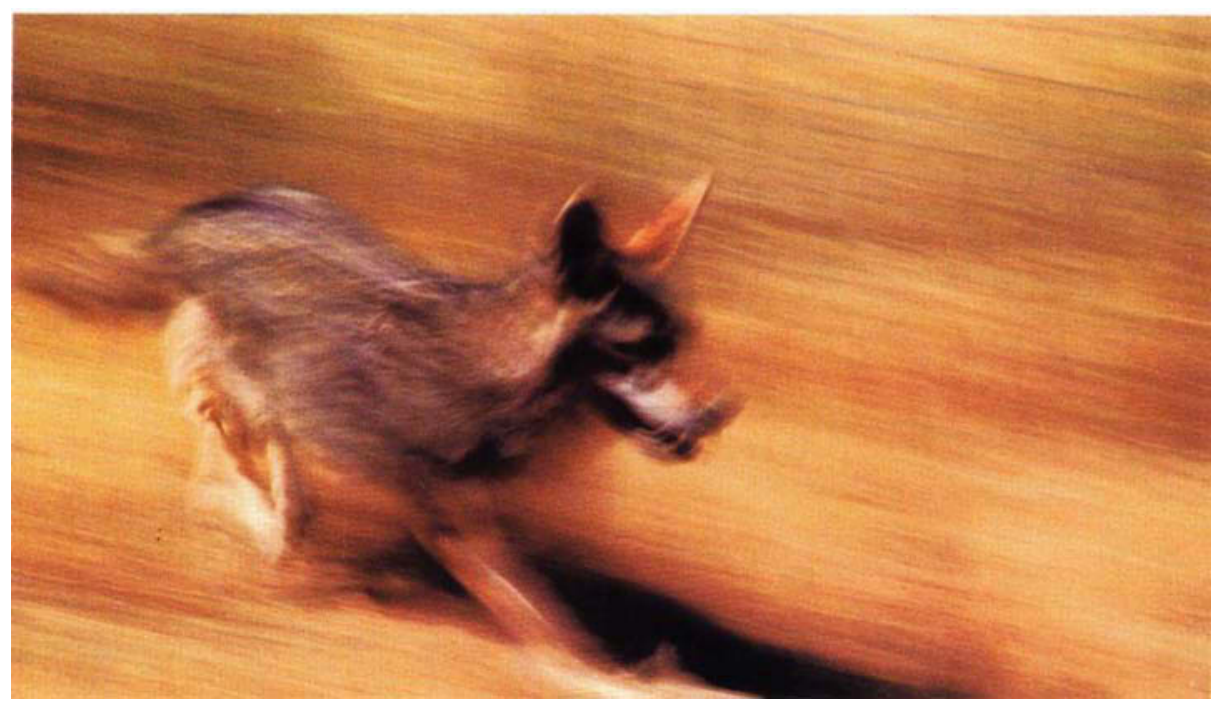

Scientists at Hopland have conducted important investigations into why coyotes kill sheep and how to stop them. Killing behavior was associated more with the pursuit of fleeing sheep than hunger, and dominant, territorial coyotes were more likely to attack.

tember 1994, coyote control was stopped on center property, as it was not compatible with research capture and radiotelemetry efforts. Coyote control by traditional methods resumed in early October 1994, and continued until late 1995, when use of the livestock protection collar (LPC) was substituted for all other lethal methods. California voters banned the active ingredient used in the LPC in November 1998, with the passage of Proposition 4.

\section{Sheep-killing behavior}

For nearly 30 years, researchers have conducted a series of studies at Hopland aimed at reducing predation on sheep in the North Coast region. A colony of captive coyotes was established at the center in 1973 when coyote pups were obtained from local trappers and reared in confinement. To begin predation studies, it was necessary to confirm whether captive animals would kill sheep if given the opportunity. Behavioral observations were conducted in fenced enclosures. When published, this information was the first documented observational study of sheep-killing behavior among coyotes. Of particular interest was that coyotes with no previous prey-killing experience readily attacked and killed sheep when given the chance. Furthermore, the stimuli that elicited attack and killing behavior were associated more with flight behavior of sheep than with coyotes' hunger. Finally, it appeared that the colony's more dominant coyotes were most likely to attack sheep (Connolly et al. 1976; Timm and Connolly 1977).

\section{A population model}

When predator studies began at HREC, it was known that coyotes were hard to control, and that coyote populations possess biological mechanisms that enabled them to compensate for human-caused mortality through increased production and survival of young. However, the integrated effect of these mechanisms was poorly understood. Therefore, we developed a simple mathematical model to simulate coyote population dynamics.

The model was used to study the probable effects of control on coyote populations. In this model, coyote removal reduced population density, thereby stimulating density-dependent changes in birth and natural death rates. Tests of varying levels of control showed that the coyote population could maintain itself indefinitely with annual kill rates of up to $70 \%$, but an annual removal of $75 \%$ exterminated the population in about 50 years. Populations reduced by control recovered to precontrol densities within 3 to 5 years after control was terminated (Connolly and Longhurst 1975). Judging from its citation frequency, this coyote model is 
among the most useful products of wildlife research at HREC.

\section{What attracts, repels coyotes}

Trappers typically use odors and scents to attract coyotes to traps or other control devices. The lures are often based on traditional recipes containing rotted meat, scent or secretions from mammals, or other odorous compounds. To chemically define the active components of coyote lures, UC Davis researchers and USDA scientists began a 10-year cooperative effort to evaluate coyote responses to various odors and to chemically characterize effective attractants. Observations of captive coyotes at Hopland from 1974 through 1983 provided important data on responses to prospective attractants and repellents.

Analysis of coyote responses to fractions of coyote urine, perfumes and scents, and many other candidate attractants revealed that the common factor was short-chain fatty acids (Fagre et al. 1982). Some odors elicited specific, predictable behavioral responses (Fagre et al. 1983; Scrivner et al. 1987). Patents were obtained on some of the most promising chemical lures (Teranishi and Howard 1986).

UC Davis scientists cooperated with USDA chemists in the mid-1970s to pilot test a capsaicin (hot pepper)-based repellent on sheep. The compound was ineffective in preventing coyote attacks. Subsequent research using cull chickens as prey revealed that even after coyotes experienced negative sensations from noxious and irritating compounds, they would not reliably learn to avoid treated prey on the basis of visual or olfactory cues (Fagre et al. 1981).

\section{Guard animals}

During the late 1980s and the 1990s, specialized breeds of dogs (such as Anatolian Shepherd and Great Pyrenees) and llamas were used as guards to reduce coyote predation on lambs and adult sheep. While surveys of sheep producers elsewhere confirm the effectiveness of guard animals in

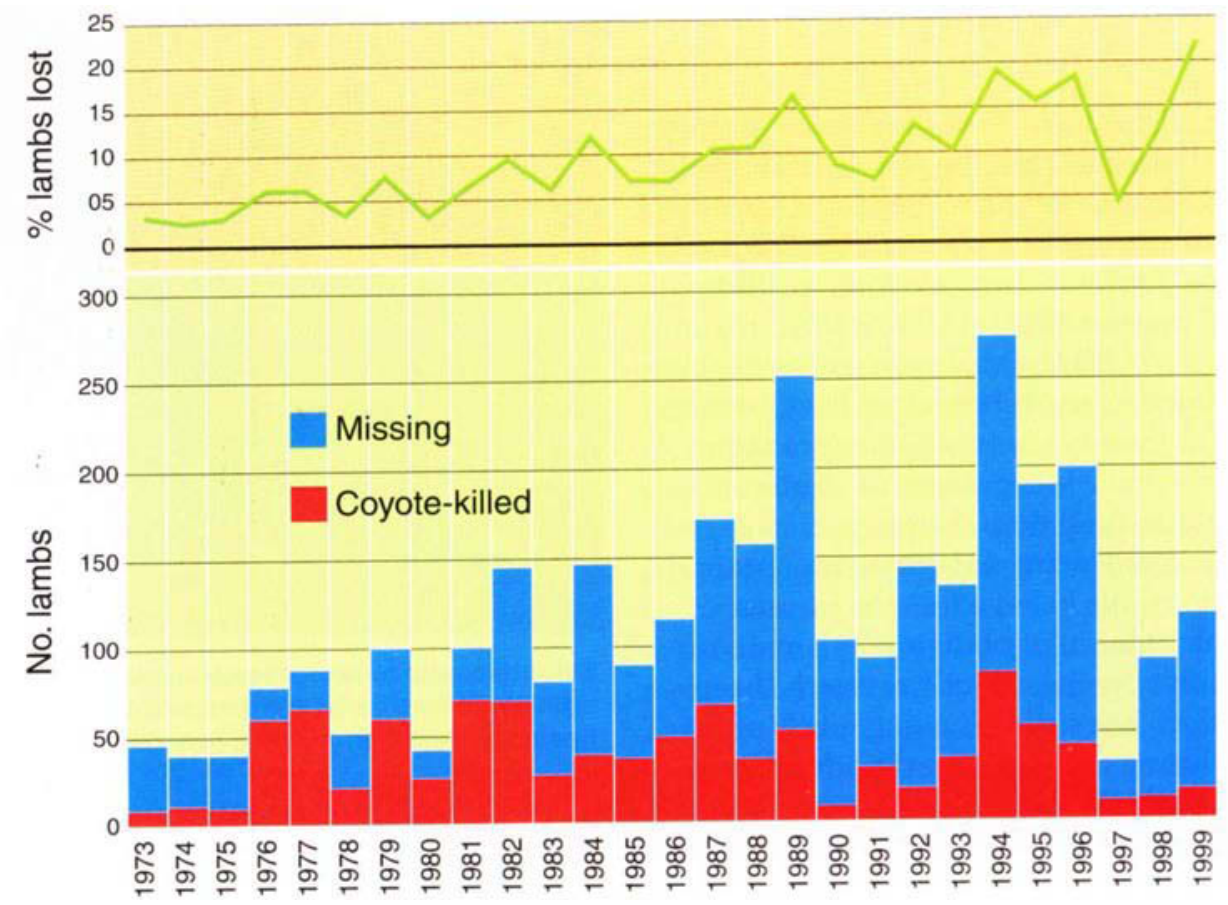

Fig. 1. Lambs lost at HREC, 1973-1999, by total number and percentage of lambs on range. Data were collected from shepherds' journals, by lambing season (December to May). Likely and confirmed kills were counted.

certain situations (Green 1990), we found they had limited value at Hopland.

Some individual guard animals exhibited behaviors effective in deterring coyote predation, but others did not. Moreover, many of the guard dogs and llamas demonstrated an array of behavioral problems, adding to the complexity of managing the research sheep flock. For example, some guard dogs attacked and killed deer fawns, and the center's wild turkey population declined, possibly due to dog harassment. Our guard llamas did not learn to discriminate between livestock-herding dogs and other canids, often exhibiting attack behavior toward our valuable herding border collies and putting them at serious risk of injury.

We theorize that the center's rugged terrain, large pastures, distribution of sheep over large areas for research purposes, and abundant predator populations are all factors that compromise the effectiveness of guard animals here (Timm and Schmidt 1989; Timm 1999).

\section{Electric fencing}

An electrified wire near ground level was added to existing wovenwire fences and tested in the mid1970 s as a means of reducing coyote entry into certain pastures. This technique was ineffective. In 1992, we constructed a high-tensile electric fence around a 250 -acre pasture to test its cost-effectiveness for reducing coyote and dog predation. While the initial cost was less than conventional woven-wire fencing, the cost advantage was soon lost because of increased maintenance required to keep the electric fence in working order.

While the electric fence successfully reduced coyote and dog depredation on sheep and lambs in the enclosed pasture, the cost-effectiveness of fencing to exclude predators is questionable, given the economics of sheep production on rangelands such as ours. However, good fences, both electric and woven wire, enhance the effective use of other predator control methods such as traps, snares and guard animals (Green et al. 1994). 


\section{Radiotelemetry and alphas}

In 1992, USDA and UC Berkeley scientists initiated an intensive field study of the coyote population at HREC. For more than 5 years, researchers made continuous efforts to capture, radio-collar, release and radio-track all coyotes that were using center property. More than 150 coyotes captures were made.

Radiotelemetry studies revealed that pairs of resident, territorial coyotes occupied most of the center's land. Subordinate animals including many juveniles were more typically found occupying spaces between established territories, and they would quickly explore territorial areas that became vacant when the resident dominant adults were removed. Radiotelemetry data also strongly suggested that most depredation on sheep and lambs was committed by relatively few individuals, which tended to be "alpha" coyotes - territorial, breeding adults (see p. 32) (Sacks et al. 1999). The results implied that to be effective, coyote control should focus on individual coyotes involved in killing livestock and should take place immediately preceding the lambing season.

\section{Livestock protection collar}

The only known tool for selectively killing coyotes that attack livestock is the LPC. The collar covers the throat of sheep or goats, with the expectation that an attacking coyote is likely to puncture the collar and receive a toxic dose of sodium fluoroacetate. The LPC was developed and field-tested over a decade of intensive research led by retired USDA and HREC wildlife researcher Guy Connolly. Sodium fluoroacetate, the active ingredient found to be safest and most effective, received federal registration for use in the LPC in 1985 (Connolly 1980, 1993; Moore 1985). Its relative selectivity and safety is documented (Burns et al. 1991; USDA 1994). The collar requires the sacrifice of the lamb in the process, because the toxicant is not lethal until several hours following ingestion.
Use of the LPC as a sol method of controlling depredating coyotes fit well with USDA and UC Berkeley's ongoing field studies at HREC, and we wished to test the effect of removing only sheepkilling coyotes while leaving other coyotes undisturbed. In October 1995 we began to deploy the collars on groups of target sheep and lambs (typically 20 to 25 head) whenever feasible, in response to repeated coyote attacks.

Twenty-one deployments between October 1995 and April 1999 resulted in 13 coyote attacks on one or more collared sheep. Three deployments were unsuccessful because the coyote attacked without puncturing the collar. However in 10 deployments, at least one collared sheep was attacked and the collar punctured. We believe our use of the LPC resulted in the death of 12 or 13 livestock-

killing coyotes. During this time, only six coyotes were removed by other lethal means after being identified as livestock predators. Our success rate for LPC use, in terms of coyotes killed per collar exposure, was similar to that documented elsewhere (Connolly 1993; Walton 1991).

Our greatest successes in reducing losses were during the 1997 and 1998 lambing seasons. When relying on traditional, lethal predator control tools and methods, such as traps, snares and shooting, we commonly removed 10 to 20 or more coyotes annually from HREC property (Conner et al. 1998). While using the LPC as our primary control tool, we removed an average of about six coyotes per year, although an exact count is difficult because most coyotes killed by LPCs are not found.

While relying on LPCs, coyote sightings and field signs indicated an increased presence of coyotes on HREC property. This supports the hypotheses that some coyotes are less prone than others to attack sheep or lambs, and that there may be positive value in having stable pairs of dominant, territory-defending coyotes present if they are not attacking sheep. However, we suspect that sooner or later, most dominant coyotes living near sheep will prey on them. Therefore, to solve predation problems, one needs the capability to remove predatory coyotes, preferably with a selective method such as the LPC.

There are some limitations to use of the collar. By federal mandate, no more than 20 collars can be used in any 100 -acre pasture, and no more than 50 on pastures between 100 and 640 acres. Because collars cost about $\$ 24$ each and require significant monitoring and labor to search for lost collars or collared sheep, most users establish a small group of collared lambs or ewes within a flock. Sodium fluoroacetate is hazardous to humans and 
other nontarget species if ingested; as such, its federal registration requires the use of appropriate protective equipment when handling collars or collared sheep. Punctured or leaking collars, or contaminated sheep carcasses, soil or vegetation must be cleaned up promptly and disposed of as hazardous waste.

California ban. In a mailing to voters, animal welfare proponents of Proposition 4 argued that sodium fluoroacetate caused "cruel, unnecessary deaths" and "immense suffering in its victims," and called padded leghold traps and poisons "indiscriminate and cruel." However, a recent study from Australia, where sodium fluoroacetate is widely used to control introduced mammal pests, concluded that pain is not associated with fluoroacetate poisoning (Gregory 1996); furthermore, USDA and UC Berkeley research conducted at HREC during the 1990s found that in more than 150 coyote captures with leg-hold traps, the incidence of injury and death was less than $5 \%$.

Unfortunately, passage of the 1998 antitrapping initiative banned all uses of sodium fluoroacetate, including its use in the LPC. It also banned sodium cyanide, which was used in M-44 spring-loaded ejector devices; M-44s are set in the ground and expel quickacting poison into the mouths of animals that tug at their bait. Both chemicals, now banned, were used in California only by government personnel. Proposition 4 also banned leghold traps, including padded traps, with no exemptions for research. We believe passage of this measure banned predator management tools with a history of safe and effective use. It also made capture of coyotes for research purposes more difficult.

\section{Predator management challenges}

The percentage of lambs lost at HREC during the 1997 lambing season (following the first full year of LPC use) was the lowest in more than 15 years (fig. 1). During the 1998 lambing season (December to May), similarly small numbers and percentages of available lambs were confirmed as coyote-killed $(1.5 \%$ in 1997 , and $1.7 \%$ in 1998); this loss was lower than or equal to our lamb loss for any year since 1992. To find two consecutive years with such low coyote-confirmed losses at HREC, one has to look back to 1974 and 1975, when coyote numbers were lower and center neighbors also raised sheep and conducted predator control, thus "buffering" the center from coyote immigration.

However, during the 1998 lambing season, a substantially higher number of lambs were missing. Carcasses could not be recovered in time to determine the cause of death, if found at all. In most years we believe approximately half of the missing lambs are lost to predators. But in 1998, an unusually high number of missing lambs are known to have died because of the sustained cold, wet weather conditions of El Niño. We did not have sufficient labor at HREC to locate and retrieve all carcasses of lambs that died because of exposure, and scavengers typically consume many such carcasses within 24 to 48 hours (Robert J. Keiffer, personal observation).

In 1998,51 lambs $(69 \%$ of those found) died of causes other than predation (primarily exposure), while the remaining 10 lamb carcasses were not found in time to determine cause of death. We are confident that the increase in lambs missing over the 1997 level was due mostly to causes other than coyote predation.

During the 1999 lambing season, considerably more lambs were lost than in either 1997 or 1998 . As in 1998, most of these lambs were in the missing category, rather than confirmed coyote kills. Because 1999 winter weather was more normal than in 1998 , we suspect that the majority of 100 missing lambs in 1999 succumbed to coyote predation.

The passage of Proposition 4 made our continued use of sodium fluoroacetate in LPCs impossible at the start of the lambing season, the most critical time to conduct coyote control. We suspect our inability to selectively remove sheep-killing coyotes during the prelambing and lambing season resulted in the higher loss rate in 1999.

The recent ban on leg-hold traps and on the selective use of toxicants has made it increasingly difficult to achieve effective coyote control, and no new methods have evolved to take 
their place. As a result, losses continue to be significant and livestock protection costs are higher than ever. Both factors contribute to the decline of sheep producers' incomes and profits.

We continue to conduct field trials in an effort to investigate new technologies that may be useful in preventing or reducing livestock loss. Recent trends in the economics of livestock production, as well as in public attitudes toward predator management, suggest that a successful resolution to this wildlife-agriculture conflict is unlikely to occur anytime soon.

\section{R.M. Timm is Superintendent and} Extension Wildlife Specialist, HREC; and G.E. Connolly is Wildlife Research Biologist (retired), USDA National Wildlife Research Center, Fort Collins, Colo., and former Staff Research Associate, Department of Wildlife and Fisheries Biology, UC Davis. The authors thank Karen Blejwas and two anonymous reviewers for providing helpful comments and suggestions.

\section{References}

Agricultural Commissioner. 1962, 1995. Crop Report, Mendocino County. Ukiah, CA.

Burns RJ, Tietjen HP, Connolly GE. 1991. Secondary hazard of livestock protection collars to skunks and eagles. J Wildl Manage 55(4):701-4.

Conner MM, Jaeger MM, Weller TJ, McCullough DR. 1998. Effect of coyote removal on sheep depredation in Northern California. J Wildl Manage 62(2):690-9.

Connolly G. 1980 . Use of Compound 1080 in Livestock Neck Collars to Kill Depredating Coyotes. US Fish \& Wildl Serv/ Denver Wildlife Res Center. 125 p.

Connolly G. 1993. Livestock protection collars in the United States, 1988-1993. Proc Gt Plains Wildl Damage Control Workshop 11:25-33.

Connolly GE, Longhurst WM. 1975. The effects of control on coyote populations. UC Div Agr Sci Bull 1872. $37 \mathrm{p}$.

Connolly GE, Timm RM, Howard WE, Longhurst WM. 1976. Sheep-killing behavior of captive coyotes. J Wild Manage 40(3):400-7.

Coolahan C. 1990. The North Coast animal damage control program. In: Giusti GA,

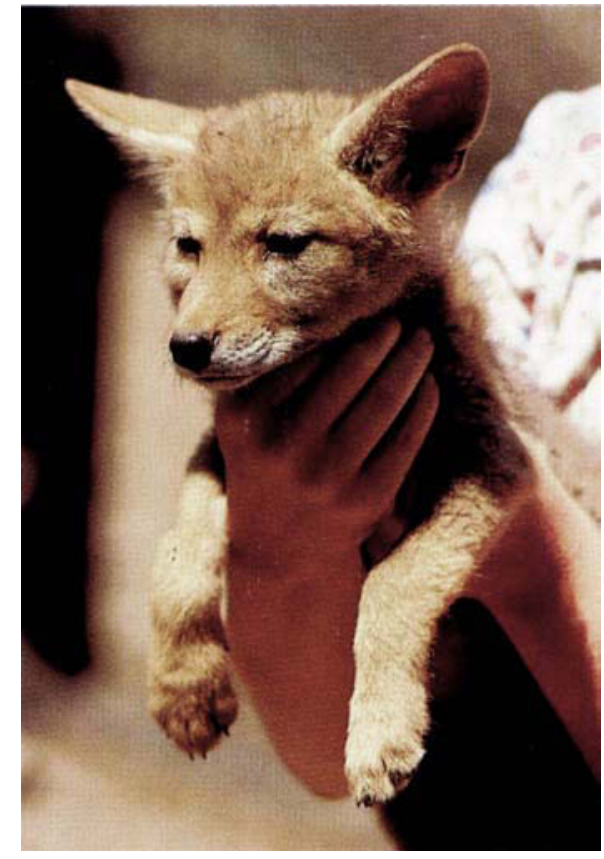

When a region's coyote population is reduced, the animals often produce more pups to compensate for the loss. With few effective methods available, sheep producers face an ongoing challenge to limit losses due to coyote depredation.

Timm RM, Schmidt RH (eds.). Predator Management in North Coastal California. Hopland Field Sta Pub 101. p 16-22.

Fagre DB, Howard WE, Barnum DA, et al. 1983. Criteria for the development of coyote lures. In: Kaukeinen DE (ed.). Vertebrate Pest Control and Management Materials. Am Soc for Testing \& Materials STP 817, Philadelphia. p 265-77.

Fagre DB, Howard WE, Marsh RE. 1981 Factors affecting coyote killing behavior: An artificial model-mimic prey system. In: Chapman JA, Pursley D (eds.). World Furbearer Conf Proc. Vol 2, Univ Maryland, Frostburg. p 950-65

Fagre DB, Howard WE, Teranishi R 1982. Development of coyote attractants for reduction of livestock losses. In: Peek JM, Dalke PD (eds.). Wildlife-Livestock Relationships Symp. Univ Idaho, Coeur d'Alene. p 319-26.

Green JS. 1990 . Reducing predation with guarding animals. In: Giusti GA, Timm RM Schmidt RH (eds.). Predator Management in North Coastal California. Hopland Field Sta Pub 101. p 62-8.

Green JS, Henderson FR, Collinge MD. 1994. Coyotes. In: Hygnstrom SE, Timm RM, Larsen GE (eds.). Prevention and Control of Wildlife Damage. Univ Nebr Cooperative Extension, Lincoln. p C51-C76.

Gregory G. 1996. Perception of pain associated with 1080 poisoning. In: Fisher $P$, Marks CA (eds.). Humaneness and Vertebrate Pest Control-Proceeding of the Seminar, Mar. 27, 1996. Rept Series No 2 Vertebrate Pest Research Unit, Victoria Instit Animal Sci, Frankston, Victoria, Australia. $p$ 62-4.

Hackett D. 1990. Predator problems on California's North Coast: Economic impacts.
In: Giusti GA, Timm RM, Schmidt RH (eds.). Predator Management in North Coastal California. Hopland Field Sta Pub 101. p 23-7.

Larson S, Salmon TP. 1988. Predators and sheep management practices in Sonoma County, Calif. Proc Vertebr Pest Conf 13:230-4.

Moore JA. 1985. Registration of Compound 1080. Environmental Protection Agency notice. Fed Reg 50:28986. July 17, 1985.

[NASS] National Agricultural Statistics Service. 1999. Sheep and Goats Final Estimates, 1994-1998. USDA/NASS Statistical Bull No 954a. $28 \mathrm{p}$.

Sacks BN, Jaeger MM, Neale JCC, McCullough DR. 1999. Territoriality and breeding status of coyotes relative to sheep predation. J Wildl Manage 63(2):593-605.

Scrivner JH, Howard WE, Murphy AH, Hays JR. 1985. Sheep losses to predators on a California range, 1973-1983. J Range Manage 38(5):418-21.

Scrivner JH, Teranishi R, Howard WE, et al. 1987. Coyote attractants and a bait-delivery system. In: Green JS (ed.). Protecting Livestock from Coyotes. USDA Ag Res Serv synopsis, US Sheep Exp Sta, Dubois, Idaho. p 38-55.

Simpson LL. 1995. Sheep and Lamb Death Loss, 1994. USDA/Nat Ag Statistics Serv, Staff Rep LDP No 95-01. 36 p.

Taylor RG, Workman JP, Bowns JE. 1978. The economics of sheep predation in southwestern Utah. J Range Manage 32(4):317-21.

Teranishi R, Howard WE. 1986. Coyote attractants. SID Res Dig 4:4-6.

Timm RM. 1990. Predator damage and research at the Hopland Field Station, UC. In: Giusti GA, Timm RM, Schmidt RH (eds.). Predator Management in North Coastal California. Hopland Field Sta Pub 101. p 3-9.

Timm RM. 1999. Controlling coyote predation on sheep in California: A model strategy. Final Rep to Calif Dept Pesticide Reg, Contract 95-0241. UC Hopland Res \& Extension Ctr. 20 p.

Timm RM, Connolly GE. 1977 . How coyotes kill sheep. Rangemans J 4(4): 106-7.

Timm RM, Schmidt RH. 1989. Management problems encountered with livestockguarding dogs on the UC Hopland Field Station. Proc Gt Plains Wildl Damage Control Workshop 9:54-8.

[USDA] US Department of Agriculture. 1994. Final Environmental Impact Statement, Animal Damage Control Program. Animal \& Plant Health inspection Serv, Washington, DC. Appendix F: Animal Damage Control "May Affect" Determinations for Federally Listed Threatened and Endangered Species, US Fish \& Wildl Serv Biological Opinion. Appendix P: Risk Assessment of Wildlife Damage Control Methods Used by USDA Animal Damage Control Program. p 272-8; 283-7.

Walton MT. 1991. Use of livestock protection collars to protect sheep and goats. Proc East Wildl Damage Control Conf 5:88-95. 